Check for updates

Cite this: RSC Adv., 2019, 9, 28814

\title{
One-pot synthesis of biomimetic glutathione peroxidase with temperature responsive catalytic behaviors
}

\author{
Shufei Jiao, ${ }^{a}$ Ruirui Zhang, ${ }^{a}$ Yanzhen Yin, (D) *a Shuming Zhong, ${ }^{a}$ Zijie Liu, ${ }^{a}$ \\ Yunying Zheng, ${ }^{a}$ Xiaoxi Hu, ${ }^{a}$ Xingtang Liang ${ }^{a}$ and Zuqiang Huang (D) *b
}

\begin{abstract}
Excessive reactive oxygen free radicals (ROS) are the main cause of various oxidative diseases. It is of great significance to develop antioxidant drugs that can intelligently regulate free radical concentrations. The biomimetic simulation of glutathione peroxidase (GPx) can provide an important theoretical basis for the development of antioxidant drugs. In order to explore a simple and efficient strategy for constructing biomimetic GPx, a microgel biomimetic GPx (PNTegel) with temperature responsive catalytic activity was prepared by a one-pot synthesis method. The PNTegel, with typical enzymatic catalytic characteristics, exhibited a maximum catalytic activity at $37{ }^{\circ} \mathrm{C}\left(v_{0}=11.51 \mathrm{mM} \mathrm{min}{ }^{-1}\right)$. The investigation of the catalytic mechanism of PNTegel suggested that the binding of different hydrophobic substrates to PNTegel was altered by the change of hydrophobicity of poly( $\mathrm{N}$-isopropylacrylamide) (PNIPAM) in the microgel scaffold of PNTegel during the temperature response process. The change of hydrophobicity was the main factor for regulating the catalytic activity of PNTegel, which resulted in a temperature responsive catalytic behavior of PNTegel. This new strategy for the simple and efficient construction of biomimetic GPx by a one-pot method provides important theoretical support for exploring the preparation of highly effective antioxidant drugs.
\end{abstract}

Received 25th July 2019
Accepted 30th August 2019

DOI: $10.1039 / c 9 r a 05775 g$

rsc.li/rsc-advances

\section{Introduction}

Glutathione peroxidase (GPx) is an important selenozyme in the human body, and was first discovered by Mills et al. ${ }^{1}$ Then, Epp et al. reported its crystal structure for the first time. ${ }^{2}$ Commonly, GPx decomposes excess oxygen free radicals (ROS) in the human body using glutathione as a reducing agent and plays an important role in preventing various diseases such as cardiac cataracts, cardiovascular and cerebrovascular diseases, inflammation and Keshan disease..$^{2-5}$ In order to provide a further theoretical basis for the development of antioxidant drugs, it is of great significance to study the catalytic mechanism of GPx and construct an effective biomimetic GPx. ${ }^{4,6-19}$ It is proved that selenocysteine in natural GPx is the catalytic center and plays an important role in maintaining high GPx catalytic activity. ${ }^{6,7,20,21}$ Through the biomimetic simulation of GPx catalytic center in natural GPx, researchers have prepared a series of biomimetic GPx. Generally, the scaffold materials for preparing biomimetic GPx mainly include small organic molecules, ${ }^{12,13,20-22}$ imprinted proteins, ${ }^{8,11}$ genetically engineered proteins, ${ }^{14,15,23}$

${ }^{a}$ Qinzhou Key Laboratory of Biowaste Resources for Selenium-enriched Functional Utilization, College of Petroleum and Chemical Engineering, Beibu Gulf University, Qinzhou 535011, China. E-mail: yinyanzhen2018@163.com

${ }^{b}$ School of Chemistry and Chemical Engineering, Guangxi University, Nanning 530004, China.E-mail: huangzq@gxu.edu.cn supramolecular polymers, ${ }^{17,19,24,25}$ block polymers, ${ }^{26-29}$ microgels, ${ }^{30-32}$ and organic-inorganic hybrid materials. ${ }^{33-36}$ Compared with natural GPx, these biomimetic GPx were endowed with obvious advantages, such as high preparation yield, strong structural stability and good industrialization prospect. Among the scaffold materials of these biomimetic GPx, the microgel scaffold exhibits unique characteristics. Due to the threedimensional structure of microgel is similar to that of natural GPx, the microgel is considered to be an efficient scaffold to construct biomimetic GPx and simulate the natural GPx catalytic behavior. Therefore, the construction of microgel-based biomimetic GPx is expecting, and our research team has carried out some exploration in this research field. ${ }^{30-32}$ Generally, the supramolecular microgel biomimetic GPxs were efficiently constructed by a host-guest supramolecular selfassembly, in which the host-guest molecules were modified to gain the catalytic function similar to the GPx. These biomimetic GPxs could successfully simulate the natural GPx by exhibiting a typical enzymatic catalytic behavior.

ROS are the by-products of normal human metabolism. Although a certain concentration of ROS plays an important role in normal physiological functions, the excessive free radicals can cause oxidative damage.,37 Generally, natural GPx remove excess ROS and regulate the free radicals at an appropriate concentration to protect the normal physiological functions of the human body. Therefore, the development of 
biomimetic GPx that could intelligently regulate the concentration of ROS by changing its catalytic activity is desirable. It is of great significance for the development of intelligent antioxidant drugs. Using different stimuli-responsive materials, researchers have developed various smart biomimetic GPx with different responsive catalytic activity, such as temperature responsive, ${ }^{27-32,38-40} \mathrm{pH}$ responsive, ${ }^{41}$ photo responsive, ${ }^{\mathbf{4 1 - 4 3}}$ ATP responsive $^{\mathbf{1 9}}$ and so on. In particular, the construction of temperature responsive biomimetic GPx and the exploration of temperature responsive catalytic mechanisms have been systematically studied. For example, researchers prepared a series of temperature responsive biomimetic GPx based on block polymers ${ }^{28,44}$ graft polymers, ${ }^{29}$ microgels ${ }^{30}$ supramolecular microgels,,$^{31,32,38}$ etc. The construction of these biomimetic GPx not only efficiently expanded the new preparation strategy of biomimetic GPx but also intelligently regulated the catalytic activity of biomimetic GPx, which provided the basement for the development of antioxidant drugs. In our group, a series of temperature responsive biomimetic GPx based on microgel scaffold were constructed by the supramolecular self-assembly of temperature responsive materials. This strategy was environmentally friendly, while the biomimetic GPx were selfassembled only under a certain concentration range and special conditions..$^{31,32,38,44}$ Moreover, the preparation process for supramolecular building blocks was complicated, which obstructed the large-scale industrial application. Therefore, exploring a new preparation strategy to simply and efficiently construct temperature responsive biomimetic GPx is still an important research work.

ATRP is one of the effective methods for preparing various structurally controllable polymers. ${ }^{45-47}$ In addition, the one-pot method presents a unique advantage in the simple and efficient preparation of functional materials. ${ }^{48-50}$ Inspired by these, a new strategy based on the combination of ATRP and one-pot method is worthwhile to be explored for the biomimetic GPx with high efficiency temperature response catalytic activity. In this work, a temperature responsive microgel biomimetic GPx was successfully constructed by a one-pot method using $N$-isopropylacrylamide, tellurium-containing polymerizable monomer (Te monomer) and acrylamide. These monomers provide the microgel with temperature response function, catalytic function and hydrophilic segment backbone, respectively. This work provides a new strategy and an important theoretical basis for the development of highly effective antioxidant drugs.

\section{Experimental section}

\section{Materials}

Sodium borohydride and 3-bromo-1-propanol were purchased from Sigma-Aldrich. Acrylic chloride and tellurium powder were purchased from Shanghai Reagent Company. Acrylic chloride was purchased from Anhui Wotu Co., Ltd. and used after being purified by vacuum distillation. $N, N^{\prime}$-Methylene diacrylamide (MBA), acrylamide (AM), hexadecyl trimethyl ammonium bromide (CTAB), 5,5'-dithio-bis(2-nitrobenzoic acid), 4-nitrothiophenol (NBT), cumyl hydroperoxide, and hydrogen peroxide were used as received from J\&K Scientific Ltd. $N$ -
Isopropylacrylamide (NIPAM) was purchased from J\&K Scientific Ltd., and used after cyclohexane/methanol recrystallization and drying. 2-Bromopropionyl bromide was purchased from Lancaster. Tris(2-dimethylaminoethyl)amine ( $\left.\mathrm{ME}_{6} \mathrm{TREN}\right)$ was prepared according to the previously reported methods. ${ }^{\mathbf{5 1}}$ Triethylamine and tetrahydrofuran were purchased from Nanning Lantian Reagent Co., Ltd., and used after rigorously dried with sodium. 3-Carboxyl-4-nitrobenzenethiol (TNB) was synthesized from 5,5'-dithiobis(2-nitrobenzoic acid) using the previously reported methods. ${ }^{20}$

\section{Instrumentations}

The ${ }^{1} \mathrm{H}$ NMR spectra for the compounds and microgel were recorded on the Bruker $300 \mathrm{MHz}$ spectrometer using a TMS proton signal as the internal standard. UV-vis spectra were obtained using a Shimadzu 2450 UV-vis-NIR spectrophotometer. Scanning electron microscopy (SEM) observations were carried out on a JEOL JSM-6700F scanning electron microscope. Transmission electron microscopy (TEM) observations were carried out on a JEOL JEM 3010 transmission electron microscope. The buffer $\mathrm{pH}$ values were determined with a METTLER TOLEDO $320 \mathrm{pH}$ meter. Dynamic light scattering experiments were performed at Malvern-ZetaSizer Nano ZS instrument.

\section{Synthesis of polymerizable small molecules (Te monomer)}

The polymerizable small molecules (Te monomer) that contain catalytic centers were synthesized according to the reported literature. ${ }^{52}$ The NMR characterization data were as follows: ${ }^{1} \mathrm{H}$ NMR (300 MHz, $\left.\mathrm{D}_{2} \mathrm{O}\right) \delta(\mathrm{ppm}) 6.45-5.83\left(6 \mathrm{H}, \mathrm{CH}_{2}=\mathrm{CH}-\right), 4.21$ (t, $\left.4 \mathrm{H}, \mathrm{COOCH}_{2}\right), 3.31\left(\mathrm{t}, 4 \mathrm{H},-\mathrm{CH}_{2} \mathrm{Te}\right), 2.09\left(\mathrm{~m}, 4 \mathrm{H},-\mathrm{CH}_{2}-\right)$.

\section{Preparation of PNTegel by one-pot method}

The preparation of the microgel scaffold for PNTegel was carried out according to the previously reported literature. ${ }^{47}$ The procedure was as follows: a magnetic stir bar, NIPAM (30 mmol), MBA (5 mmol), Te monomer ( $1 \mathrm{mmol}), \mathrm{Me}_{6}$ TREN (0.2 $\mathrm{mmol})$, water $(450 \mathrm{~mL})$ and DMF $(30 \mathrm{~mL})$ were added to the reaction flask. The oxygen in the reaction system was removed by continuously purging nitrogen gas for $30 \mathrm{~min}$. Then, $\mathrm{CuBr}$ $(0.2 \mathrm{mmol})$ was added into the flask under the protection of nitrogen gas flow, followed by stirring for 40 minutes to form a complex of catalyst and ligand. The polymerization was then initiated by adding an initiator, benzyl 2-bromopropanoate (0.05 mmol, dissolved in $20 \mathrm{~mL}$ of DMF). ${ }^{27}$ After reacting for 8 hours at $30{ }^{\circ} \mathrm{C}$, the reaction flask was opened under a nitrogen stream and CTAB $(0.06 \mathrm{mmol})$ was added into the flask. Subsequently, the temperature of the reaction system was raised to $70{ }^{\circ} \mathrm{C}$, and the reaction was continued for 5 hours. Further, an aqueous solution $(100 \mathrm{~mL})$ of AM $(30 \mathrm{mmol})$ was added to the reaction system under a nitrogen stream, and the reaction was continued for 24 hours at $70{ }^{\circ} \mathrm{C}$. After that, the polymerization was terminated by the treatment of liquid nitrogen, and then the reaction solution was concentrated on a rotary evaporator. The resultant solution was dialyzed for five days to remove impurities. The target product (PNTegel) with the yield of $64.50 \%$ was obtained after lyophilization. The target 
product was stored in refrigerator. The content of tellurium in the catalytic center of PNTegel was determined to be $1.49 \times$ $10^{-4} \mathrm{mmol} \mathrm{mg}^{-1}$ according to the reported method. ${ }^{38}$

\section{Determination of the LCST for PNTegel}

The optical transmissions (wavelength at $600 \mathrm{~nm}$ ) of microgel polymer solution (PNTegel, $1 \mathrm{mg} \mathrm{mL}^{-1}$ ) were measured at different temperatures using Shimadzu 2450 UV-vis-NIR spectrophotometer, which was employed to determine the LCST of PNTegel. All test samples were thermostated in a circulator bath with different temperatures prior to measurements. The LCST is defined as the temperature at which the change in transmittance of the polymer solution just occurs at the inflection point.

\section{Determination of GPx activity}

The catalytic activity of PNTegel was determined by the method that established by professor Hilvert with a slight modification. ${ }^{6}$ The enzyme catalytic reaction was performed in a $1 \mathrm{~mL}$ quartz cuvette. Typically, $700 \mu \mathrm{L}$ of phosphate buffer solution $(\mathrm{pH}=$ 7.0), $100 \mu \mathrm{L}$ of PNTegel solution $(10 \mu \mathrm{M})$, and $100 \mu \mathrm{L}$ of TNB solution (1.5 mM) were sequentially added to the quartz cuvette. After keeping at a fixed temperature for three minutes, $100 \mu \mathrm{L}$ of cumene hydroperoxide (CUOOH) $(2.5 \mathrm{mM})$ was added to the quartz cuvette to trigger the enzyme-catalyzed reaction. The measurement of the ultraviolet absorption at $410 \mathrm{~nm}$ for the aforementioned system was performed on Shimadzu $2450 \mathrm{UV}$ vis-NIR spectrophotometer to calculate the reaction rate. Simultaneously, the ultraviolet absorption of the system without PNTegel was also measured to determine the reaction rate $\left(\varepsilon_{410}=13600 \mathrm{M}^{-1} \mathrm{~cm}^{-1}, \mathrm{pH}=7.0\right)$. The catalytic rate of PNTegel was calculated by subtracting the reaction rate of the system that without PNTegel from the reaction rate of the system containing PNTegel.

\section{Determination of repeatability of activity}

The measurement of the repeatability was carried out when the temperature was converted repeatedly between 25 and $37^{\circ} \mathrm{C}$. Firstly, the stock solution of PNTegel was maintained at $25{ }^{\circ} \mathrm{C}$, and the catalytic rate was determined at $25{ }^{\circ} \mathrm{C}$ according to the method mentioned above. Secondly, the temperature of the PNTegel stock solution was increased to $37^{\circ} \mathrm{C}$, and the catalytic rate was also determined at $37{ }^{\circ} \mathrm{C}$. Thirdly, the PNTegel stock solution was then decreased to $25{ }^{\circ} \mathrm{C}$ for determining the catalytic rate at $25{ }^{\circ} \mathrm{C}$ using the identical method. The catalytic rates of the PNTegel stock solution were determined by converting the temperature repeatedly between 25 and $37^{\circ} \mathrm{C}$ for several times.

\section{Results and discussion}

\section{Construction of PNTegel based on one-pot method}

Due to the important antioxidant physiological effects of glutathione peroxidase (GPx), Epp et al. first studied the crystal structure of GPx, indicating that the selenocysteine is the catalytic center of GPx. ${ }^{2}$ In addition, by constructing biomimetic GPx with similar catalytic functions to the natural GPx, researchers have further proved that the hydrophobic cavity consisted by hydrophobic amino acid residues also plays an important role in maintaining the high catalytic activity of natural GPx. ${ }^{28,44}$ Therefore, based on these researches, in this work, we designed a polymerizable monomer Te monomer as an alternative of the catalytic center of natural GPx (as shown in Fig. 1). Since PNIPAM is a polymer with temperature responsive property, the hydrophobic microenvironment formed by the hydrophobic polymer chain of PNIPAM in the temperature response process was employed to simulate the hydrophobic cavity of natural GPx. In addition, NIPAM and AM were the main functional monomers for constructing the microgel scaffold of biomimetic GPx. TNB and NBT were used as the thiophenol substrates, and $\mathrm{CUOOH}$ was employed as the peroxide substrate. These substrates were employed to determine the GPx catalytic activity of biomimetic GPx. MBA was a crosslinking molecule for preparing microgel. Except for the catalytic center, the Te monomer also acted as a cross-linking agent. A schematic diagram of the preparation of microgel scaffold for PNTegel by one-pot method is shown in Scheme 1 .

As shown in Scheme 1, the preparation process of PNTegel by one-pot method was mainly divided into three stages. First, PNIPAM was synthesized by using ATRP, wherein the monomers of MBA and Te monomer were copolymerized in this process. Therefore, the catalytic center was anchored into the polymer scaffold of PNIPAM. Then, the temperature of the reaction system was raised to $70{ }^{\circ} \mathrm{C}$, and the reaction was carried out for about 5 hours. The solution of reaction system became turbid due to the poor solubility of PNIPAM polymer in the aqueous solution with $70^{\circ} \mathrm{C}$. Under this condition, CTAB, a surfactant, was introduced into the reaction system to emulsify the reaction solution, which caused the reaction to be carried out mainly in the microemulsion. This therefore facilitated the formation of the main scaffold structure of the microgel. After a reaction of 5 hours, the monomer AM was added to the system. The polymerization reaction was continued for another 24 hours at $70{ }^{\circ} \mathrm{C}$, which fully anchored the polyacrylamide (PAM) into the scaffold of PNTegel and formed a shell layer of microgel. After that, the polymerization reaction was terminated by liquid nitrogen. After concentrating in a rotary evaporator, the resultant solution was dialyzed against a dialysis bag (molecular weight cutoff of 100 000), and freeze-dried to obtain the microgel material of PNTegel. In order to verify the successful preparation of microgels, the

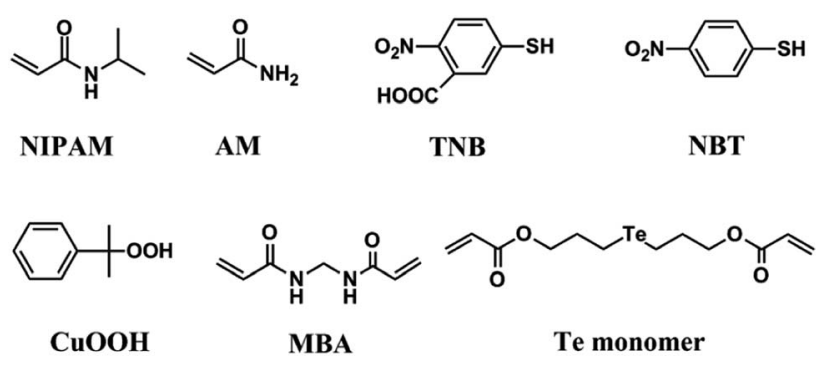

Fig. 1 The structures of the functional monomers NIPAM, AM, Te comonomer, $\mathrm{CUOOH}, \mathrm{MBA}$ and substrates (NBT, TNB). 

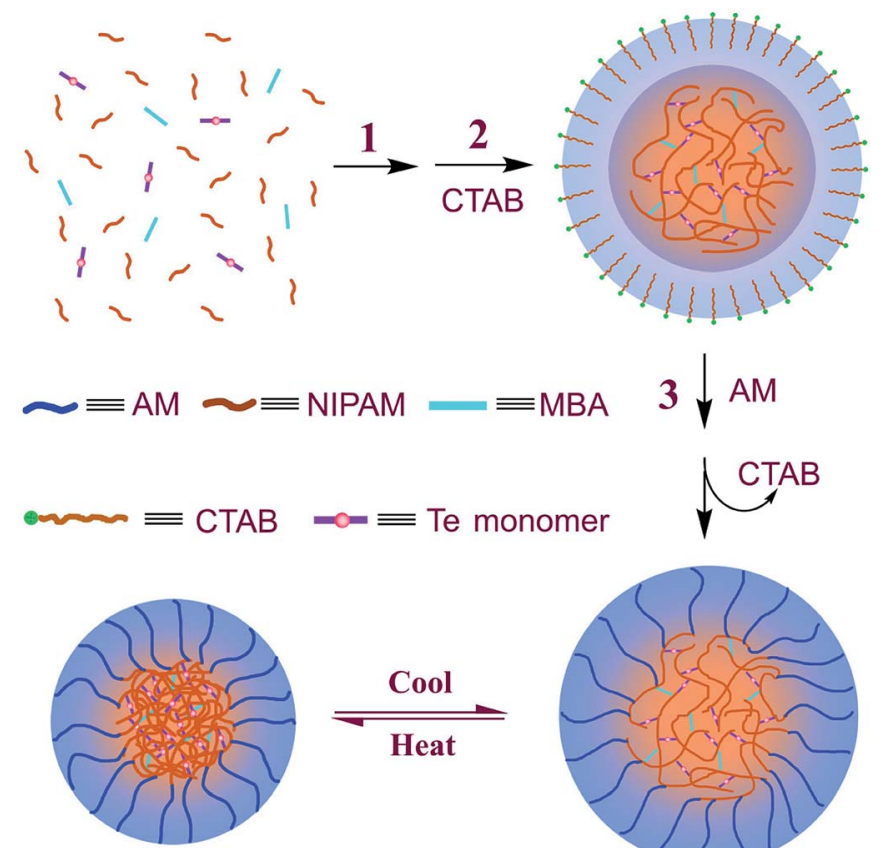

high catalytic activity

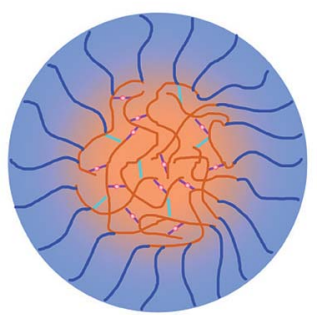

low catalytic activity

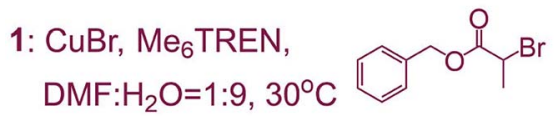

2: CTAB $70^{\circ} \mathrm{C}$

3: $\mathrm{AM} 70^{\circ} \mathrm{C}$

Scheme 1 The graphical representation of the one-pot preparation process and reversible responsive behaviour of PNTegel.

microgel polymer scaffold of PNTegel was characterized by NMR, SEM, TEM, DLS and so on.

Firstly, as shown in Fig. 2, the structure of PNTegel was characterized by NMR. The proton signal of $d$ was the hydrogen

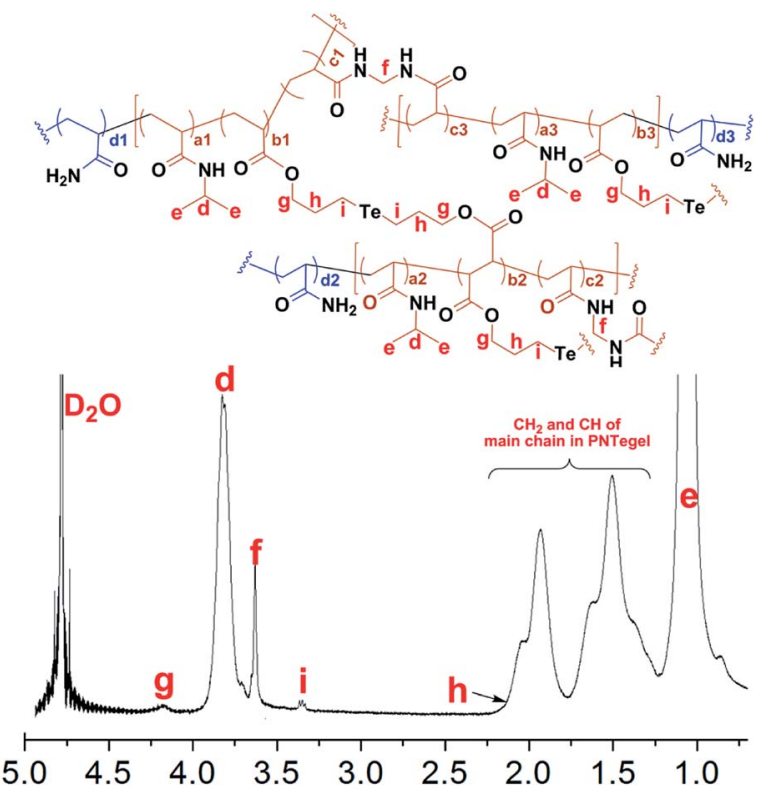

Fig. $2{ }^{1} \mathrm{H}$ NMR spectrum of PNTegel in $\mathrm{D}_{2} \mathrm{O}$. signal peak of methine in PNIPAM. The signal peaks of chemical shift between 0.8 and $2.2 \mathrm{ppm}$ were mainly attributed to the hydrogen connected with the main carbon chain of microgel and the methyl hydrogen e of PNIPAM. The proton signal of $f$ was ascribed to the methylene hydrogen of MBA, and $g$ was the hydrogen of methylene group attached to the ester group in Te monomer. The hydrogen signal peak of $i$ was attributed to the hydrogen of the methylene group attached to the tellurium in Te monomer. And the hydrogen signal peak of the other methylene group of Te monomer was masked by the signal of the hydrogen in the polymer main chain. These results demonstrated that Te monomer, the catalytic center, was successfully introduced into the microgel scaffold.

Furthermore, the morphology of PNTegel was further characterized by SEM and TEM. As shown in Fig. 3, the microgel basically exhibited a spherical structure with the diameter of about $200 \mathrm{~nm}$, indicating the successful preparation of a uniform microgel material by one-pot method. In addition, the average hydrodynamic diameter of the PNTegel microgel was also characterized by a dynamic light scattering (see Fig. 4a). It suggested that the average hydrodynamic diameter of PNTegel was about $250 \mathrm{~nm}$ at $25{ }^{\circ} \mathrm{C}$. This result was slightly larger than the observation of SEM and TEM, which might be due to the swelling of the PNTegel during the measurement of the hydrodynamic diameter. Similar results have been reported by previous works. ${ }^{32,38}$ The characterization of the hydrodynamic diameter further suggested the successful preparation of microgel scaffold of biomimetic GPx materials.

Finally, the phase transition of PNIPAM in PNTegel was characterized by the change of optical transmittance of PNTegel solution (Fig. 5). The optical transmittance of PNTegel solution was higher when the temperature was lower than $33^{\circ} \mathrm{C}$, while the optical transmittance of PNTegel solution decreased as the increase of temperature and tended to be stable when the temperature was higher than $38{ }^{\circ} \mathrm{C}$. The profile of the optical transmittance as a function of temperature indicated that the LCST of PNTegel was about $34.5^{\circ} \mathrm{C}$. This result suggested that the polymer chain of PNIPAM could be turned into a hydrophobic structure as the increase of temperature, which provided a hydrophobic microenvironment in PNTegel. This hydrophobic structure might play a significant role in simulating the hydrophobic cavity of natural GPx. The investigation of the hydrophobicity for the polymer scaffold in PNTegel provided

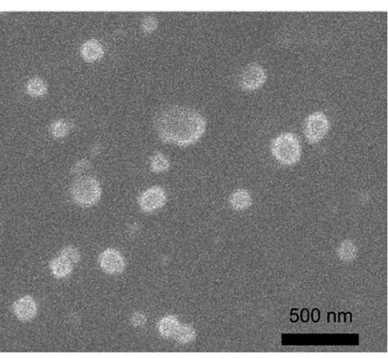

A

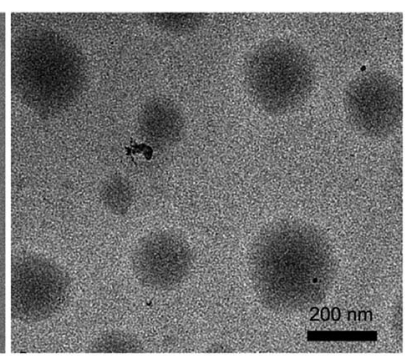

B
Fig. 3 SEM (A) and TEM (B) images of PNTegel. 


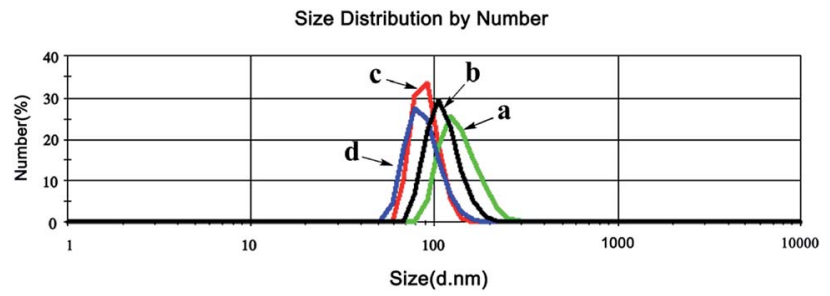

Fig. 4 Hydrodynamic diameters of PNTegel at varying temperature ((a) $25^{\circ} \mathrm{C}$; (b) $35^{\circ} \mathrm{C}$; (c) $37^{\circ} \mathrm{C}$; (d) $45^{\circ} \mathrm{C}$ ) determined using a MalvernZetaSizer Nano ZS instrument.

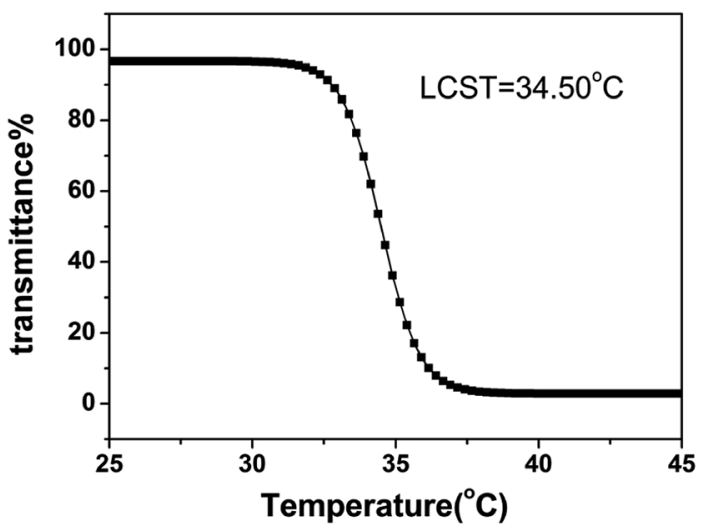

Fig. 5 Temperature dependences of optical transmittance at $600 \mathrm{~nm}$ obtained for PNTegel at the concentration of $1 \mathrm{mg} \mathrm{mL}^{-1}$.

the basic information for the following discussion of the temperature responsive catalytic mechanism.

Taken together, the results of NMR, SEM, TEM and DLS proved that the microgel scaffold of PNTegel was successfully prepared based on one-pot method. These results also provided a support for studying the temperature responsive catalytic behavior and catalytic mechanism.

In order to construct an efficient biomimetic GPx, Te monomer was designed to be the catalytic center. The catalytic activity of PNTegel was determined according to the modified method reported by Hilvert et al. ${ }^{6}$ A typical enzyme catalytic reaction for the determination of catalytic activity was shown in

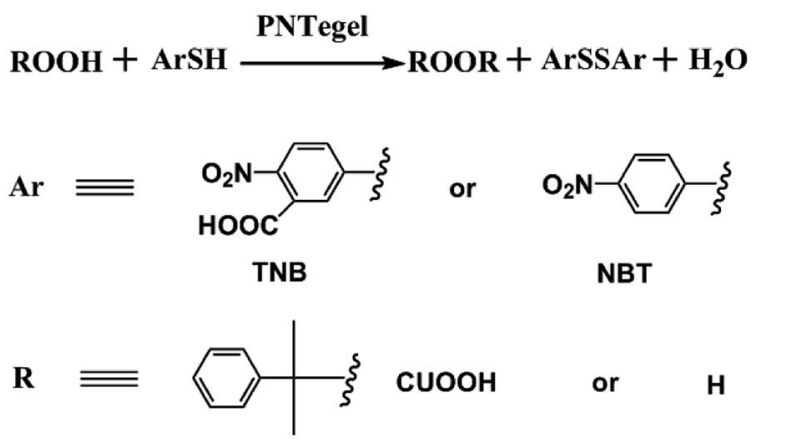

Fig. 6 Determination of GPx catalytic rate for the reduction of $\mathrm{ROOH}$ using ArSH as substrate.
Fig. 6. Among the catalytic substrates, TNB and NBT were employed to simulate the glutathione substrate, while $\mathrm{CUOOH}$ and $\mathrm{H}_{2} \mathrm{O}_{2}$ were used to mimic the peroxide substrate during the natural GPx catalytic process. Compared with $\mathrm{H}_{2} \mathrm{O}_{2}$ and TNB, CUOOH and NBT were the more hydrophobic substrates. Herein, using the hydrophobicity difference of these substrates, the catalytic mechanism and catalytic process for PNTegel could be investigated. The data of the catalytic activity for PNTegel under different conditions are listed in Table 1.

As shown in Table 1, the measurement data of the catalytic activity $\left(v_{0}\right)$ for PNTegel in the temperature range of 25 to $45^{\circ} \mathrm{C}$ was used to investigate the temperature responsive catalytic behavior of PNTegel. The results suggested that the catalytic rates of PNTegel exhibited a trend of typical temperature responsive catalytic behavior.

Aiming at evaluating the catalytic ability of PNTegel more objectively, the catalytic rates of PNTegel and the previously reported artificial GPx mimics were summarized in Table 2. Herein, the optimum catalytic activities of various telluriumcontaining GPx mimics were determined under the identical conditions using $\mathrm{CUOOH}$ and TNB as catalytic substrates. It was observed that the slightly enhanced catalytic rate was obtained when the traditional small molecule artificial GPx (PhSeSePh) was employed. Compared with PhSeSePh, remarkable catalytic rates were achieved when other tellurium-containing artificial GPx in Table 2 were used. Typically, such artificial GPx can be divided into two categories. One of them is the artificial GPx anchored with merely two catalytic elements (catalytic center and hydrophobic environment), i.e. PNTegel, PNIPAM-CD-g-Te,

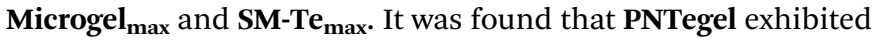
the most excellent catalytic ability among such artificial GPx with two catalytic elements. Moreover, the other kind of artificial enzyme in Table 2 is the artificial GPx modified with three

Table 1 The catalytic rates $\left(v_{0}\right)$ for the reduction of $\mathrm{ROOH}(250 \mu \mathrm{M})$ by $\mathrm{ArSH}(150 \mu \mathrm{M})$ in the presence of the PNTegel at $\mathrm{pH} 7.0$ (50 mM PBS)

\begin{tabular}{lllr}
\hline Temperature $\left({ }^{\circ} \mathrm{C}\right)$ & ArSH & ROOH & $v_{0}{ }^{a}\left(\mathrm{mM} \mathrm{min}^{-1}\right)$ \\
\hline 25 & TNB & CUOOH & $2.32 \pm 0.04$ \\
28 & TNB & CUOOH & $2.45 \pm 0.11$ \\
30 & TNB & CUOOH & $2.47 \pm 0.09$ \\
32 & TNB & CUOOH & $3.51 \pm 0.10$ \\
34 & TNB & CUOOH & $5.24 \pm 0.11$ \\
36 & TNB & CUOOH & $9.66 \pm 0.26$ \\
37 & TNB & CUOOH & $11.51 \pm 0.29$ \\
38 & TNB & CUOOH & $11.24 \pm 0.31$ \\
40 & TNB & CUOOH & $10.61 \pm 0.27$ \\
42 & TNB & CUOOH & $10.07 \pm 0.45$ \\
45 & TNB & CUOOH & $8.55 \pm 0.48$ \\
37 & TNB & $\mathrm{H}_{2} \mathrm{O}_{2}$ & $2.34 \pm 0.09$ \\
37 & NBT & CUOOH & $14.94 \pm 0.44$ \\
37 & NBT & $\mathrm{H}_{2} \mathrm{O}_{2}$ & $5.86 \pm 0.22$
\end{tabular}

${ }^{a}$ Mean \pm SD, each sample was determined for three times, and the mean value was calculated to evaluate the catalytic ability of PNTegel. The rate of auto-oxidation of ArSH was deducted during the determination of the catalytic rate. It was assumed that one molecule of the tellurium was used as a catalytic center of enzyme to calculate the activity. 
Table 2 The initial rates $\left(v_{0}\right)$ for the reduction of $\mathrm{ROOH}$ s by ArSH in the presence of PNTegel and other tellurium-containing catalysts

\begin{tabular}{lllll}
\hline Catalysts & Temperature $\left({ }^{\circ} \mathrm{C}\right)$ & ArSH & ROOH & $v_{0}{ }^{a}\left(\mathrm{mM} \mathrm{min}^{-1}\right)$ \\
\hline PNTegel & 37 & TNB & CUOOH & $11.51 \pm 0.13$ \\
PhSeSePh & 36 & TNB & CUOOH & $0.011 \pm 0.001$ \\
PNIPAM-CD-g-Te $^{b}$ & 35 & TNB & CUOOH & $6.23 \pm 0.25$ \\
Microgel $_{\text {max }}$ & 32 & TNB & CUOOH & $8.09 \pm 0.8$ \\
SM-Te $^{d}$ & 38 & TNB & CUOOH & $5.60 \pm 0.29$ \\
PN1 $^{e}$ & 37 & TNB & CUOOH & $24.1 \pm 1.8$ \\
SGPx $^{f}$ & 36 & TNB & CUOOH & $18.75 \pm 0.29$
\end{tabular}

${ }^{a}$ Mean $\pm \mathrm{SD}$, each sample was determined three times, and the mean value was calculated to evaluate the catalytic ability of PNTegel. The rate of auto-oxidation of ArSH was deducted during the determination of the catalytic rate. It was assumed that one molecule of the tellurium was used as a catalytic center of enzyme to calculate the activity. ${ }^{b}$ The supramolecular GPx mimic based on asupramolecular graft copolymer. ${ }^{29}{ }^{c}$ The microgel artificial GPx (Microgel) constructed in our previous report. ${ }^{30} d$ The supramolecualr microgel artificial GPx constructed in our previous report. ${ }^{31}{ }^{e}$ The GPx mimic based on polystyrene nanoparticle via microemulsion polymerization. ${ }^{53}{ }^{f}$ The smart supramolecular artificial GPx with temperature responsive catalytic activity based on host-guest interaction and a blending process. ${ }^{54}$

catalytic elements (catalytic center, binding site and hydrophobic environment), i.e. PN1 and SGPx. Noticeably, binding site was specially modified into the scaffold of such artificial GPx. Generally, such binding site endowed further enhanced catalytic rates with PN1 and SGPx. And the catalytic ability of PNTegel was reasonable lower than that of PN1 or SGPx since the binding site was absent in PNTegel. Herein, the main purpose of this work was to explore an efficient and simply method for constructing artificial GPx. Therefore, considering that the reasonable efficient catalytic ability was achieved based on one-pot synthesis, PNTegel was still a successful artificial GPx with temperature responsive catalytic behavior.

Moreover, in order to study the catalytic mechanism of PNTegel, the catalytic activity of PNTegel in reaction systems containing different substrates was also determined. Generally,

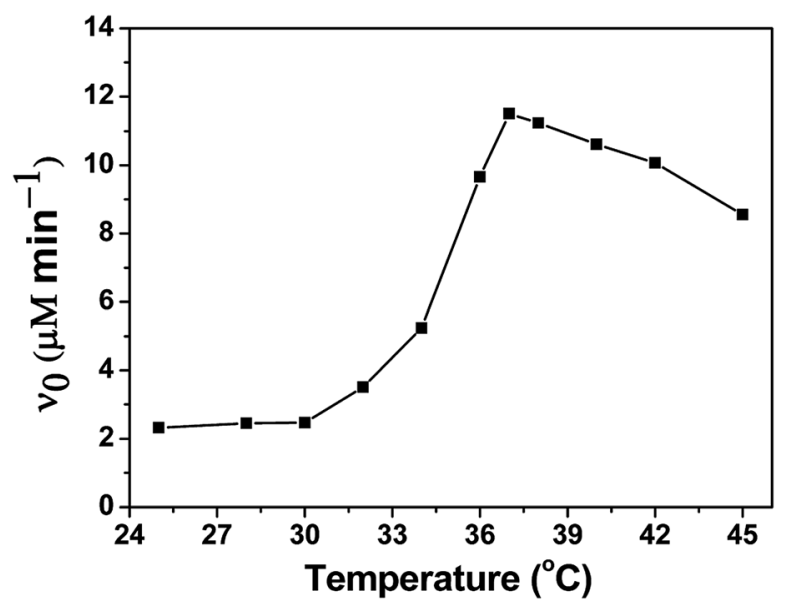

Fig. 7 The catalytic rate of PNTegel as a function of temperature for the catalytic reduction of $\mathrm{CUOOH}(0.25 \mathrm{mM})$ by TNB $(0.15 \mathrm{mM})$ with a catalytic center of $1.00 \mu \mathrm{M}$. the catalytic activity was determined by the combination of different substrates such as TNB and CUOOH, TNB and $\mathrm{H}_{2} \mathrm{O}_{2}$, NBT and CUOOH, NBT and $\mathrm{H}_{2} \mathrm{O}_{2}$, which were employed to study the influence of different hydrophobic substrates in the catalysis process of PNTegel. To more intuitively demonstrate the temperature responsive characteristics of the catalytic rate for PNTegel, the catalytic activity of PNTegel in the system of $\mathrm{CUOOH}$ and TNB as a function of temperature is provided in Fig. 7. Obviously, the catalytic rate of PNTegel was just slightly changed when the temperature was lower than $32^{\circ} \mathrm{C}$. Whereas, the catalytic rate of PNTegel increased significantly with the increasing of temperature when the temperature was above $32{ }^{\circ} \mathrm{C}$. It was noticed that the maximum catalytic activity $(11.51$ $\mu \mathrm{M} \mathrm{min}^{-1}$ ) was achieved at $37^{\circ} \mathrm{C}$. However, the catalytic rates of PNTegel tended to be significantly decreased as the further promotion of temperature. The reason for these results was discussed in the following section.

Furthermore, to probe the catalytic mechanism of PNTegel promoting the reaction mentioned in Fig. 6, detailed kinetic
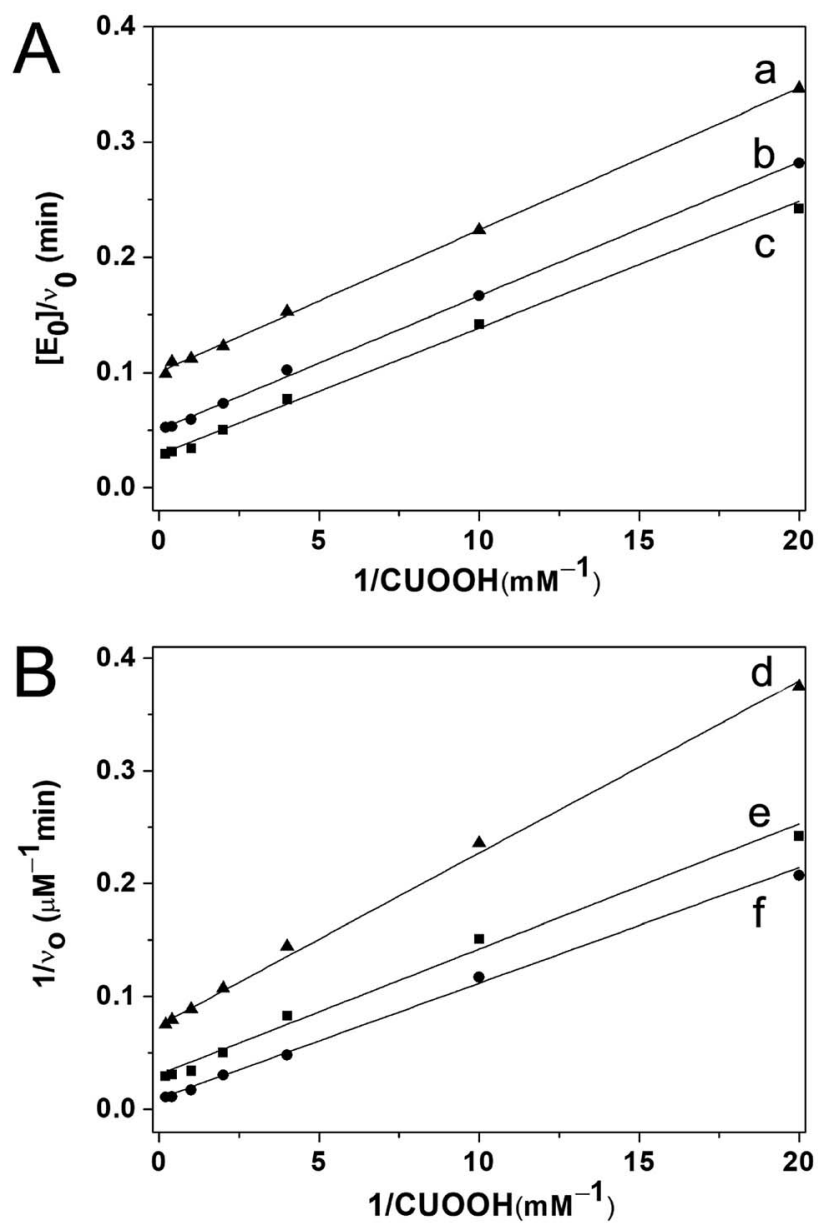

Fig. 8 (A) $\left[E_{0}\right] / v_{0}$ (min) vs. $1 /[\mathrm{CUOOH}]\left(\mathrm{mM}^{-1}\right)$ for $1 \mu \mathrm{M}$ PNTegel in PBS, $\mathrm{pH} 7.0$ and $37^{\circ} \mathrm{C}$, at $[\mathrm{TNB}]=0.04 \mathrm{mM}$ (a), $0.10 \mathrm{mM}$ (b), $0.15 \mathrm{mM}$ (c). (B) Lineweaver-Burk plots obtained for the catalytic reaction in the presence of different concentration of PNTegel ([PNTegel] $=0.5 \mu \mathrm{M}$ (d), $1 \mu \mathrm{M}(\mathrm{e}), 2 \mu \mathrm{M}(\mathrm{f}))$ at $\mathrm{pH} 7.0$ and $37^{\circ} \mathrm{C}$. The initial $\mathrm{CUOOH}$ concentration was fixed to $0.25 \mathrm{mM}$. 
experiments were conducted. These experiments were designed and carried out according to the methods reported by Dong and coworkers. $^{20}$ They had confirmed that the catalyst-substrate complex existed during the catalytic cycle through detailed kinetic studies. Double-reciprocal plots of initial rate versus concentration of $\mathrm{CUOOH}$ at all the individual concentration was illustrated in Fig. 8. It suggested that the catalytic rates increased linearly with the concentration of $\mathrm{CUOOH}$. And the rapidly increased catalytic rates were observed in the initial stages (see Fig. 8B and 9) while the concentration of $\mathrm{CUOOH}$ was increased (from 0 to $2.5 \mathrm{mM}$ ). However, the catalytic rates almost did not change when concentration of CUOOH was further increased. From this observation, it was clearly shown that this catalytic reaction featured the characteristic parallel lines of ping-pong mechanism. And it suggested that the covalent intermediate (-Te-S-Ar) was presented in the catalytic cycle. $^{20}$

In addition, the enzymatic properties of PNTegel were characterized using TNB and $\mathrm{CuOOH}$ as substrates at $37{ }^{\circ} \mathrm{C}$ (Fig. 9). The PNTegel exhibited a typical catalytic activity of enzyme. The apparent kinetic constants of PNTegel in the test system containing TNB and $\mathrm{CUOOH}$ were as follows: $V_{\max }=$ $32.15 \mu \mathrm{M} \mathrm{min}{ }^{-1}, k_{\mathrm{cat}}^{\mathrm{app}}=32.15 \mathrm{~min}^{-1}, K_{\mathrm{m} \mathrm{CUOOH}}=356.91 \mu \mathrm{M}$, $k_{\mathrm{cat}}^{\mathrm{app}} / K_{\mathrm{m} \text { сUоOH }}=9.01 \times 10^{4} \mathrm{M}^{-1} \mathrm{~min}^{-1}$, and the turnover number per catalytic center tellurium was calculated to be $84.75 \mathrm{~min}^{-1}$.

\section{Catalytic mechanism of PNTegel}

Based on the research on the crystal structure of GPx and the investigation of biomimetic GPx, it was indicated that hydrophobic cavity derived from the hydrophobic amino acid residues of ${ }^{150} \mathrm{Phe},{ }^{148} \mathrm{Trp}$, and ${ }^{34}$ Leu played an important role in maintaining the high catalytic activity., ${ }^{\mathbf{1 , 2}}$ In this study, the hydrophobic structure of the natural GPx was simulated using the hydrophobic microenvironment derived from the PNIPAM polymer scaffold during the temperature responsive process. For natural enzymes, slight structural changes may lead to

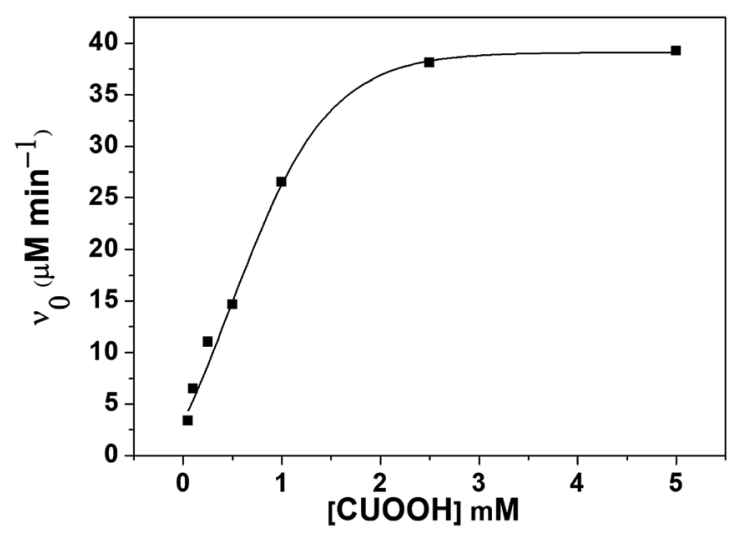

Fig. 9 The catalytic rate as a function of concentration of $\mathrm{CUOOH}$ in the presence of the PNTegel. The initial concentration of TNB was fixed to be $0.15 \mathrm{mM}$, the concentration of $\mathrm{CUOOH}$ was $0.05,0.10$, $0.25,0.5,1,2.5$ and $5 \mathrm{mM}$, respectively. significant alterations in catalytic activity. Therefore, we hypothesize that the hydrophobic change of PNIPAM polymer scaffold should be a key factor in regulating the temperature responsive catalytic activity of PNTegel. In order to confirm this suppose, the catalytic mechanism of was discussed by the combination of the changes of optical transmittance, hydrodynamic diameter and catalytic activity with temperature in the catalytic process of PNTegel.

The optical transmittance of PNTegel solution was close to $100 \%$ when the temperature was lower than the typical temperature value of the LCST of PNIPAM (about $32{ }^{\circ} \mathrm{C}$ ). Under this condition, the amide group in PNTegel interacted with the surrounding water molecules by hydrogen bond, which swelled the microgel scaffold in aqueous solution. Therefore, the hydrodynamic diameter of PNTegel was determined to be a relatively large value of about $250 \mathrm{~nm}$ (Fig. 4a). In addition, the PNTegel presented a poor catalytic activity due to the absence of hydrophobic microenvironment for effectively gathering the substrates when the temperature was lower than $32{ }^{\circ} \mathrm{C}$.

Subsequently, the temperature was elevated to above $32{ }^{\circ} \mathrm{C}$, the hydrogen bonds between amide group in PNTegel and surrounding water molecules was cleaved, which endowed the PINPAM polymer in the PNTegel a hydrophobic property. Hence, the PINPAM polymer chains in the PNTegel were shrunk, which resulted in a remarkable decrease of the optical transmittance of PNTegel solution (Fig. 5) and a decline of the hydrodynamic diameter of PNTegel. For instance, the hydrodynamic diameters of PNTegel at $35{ }^{\circ} \mathrm{C}$ (Fig. 4b) and $37{ }^{\circ} \mathrm{C}$ (Fig. 4c) were about 230 and $170 \mathrm{~nm}$, respectively, which are smaller than that of PNTegel at $25{ }^{\circ} \mathrm{C}$ (about $250 \mathrm{~nm}$ ). Obviously, the PNIAM with a temperature responsive property offered a hydrophobic microenvironment for the PNTegel under the temperature higher than the LCST. These hydrophobic microenvironments in the PNTegel could readily gather the hydrophobic substrate and consequently enriched the enzyme-catalyzed substrate molecule around the catalytic center. Therefore, the catalytic activity of PNTegel reached a maximum value of $11.51 \mu \mathrm{M} \mathrm{min}{ }^{-1}$ at $37{ }^{\circ} \mathrm{C}$, in which the appropriate hydrophobic microenvironment was formed.

Furthermore, as the further rise of temperature (above 37 ${ }^{\circ} \mathrm{C}$ ), the optical transmittance of PNTegel solution was basically stable at a low value. Meanwhile, the PNTegel presented a smaller hydrodynamic diameter at $45{ }^{\circ} \mathrm{C}$ (Fig. 4d) in comparison to that of PNTegel existed in the aqueous solution with a lower temperature. This may be attributed to the fact that the hydrophobicity of PNIPAM polymer was further enhanced, which resulted in a more compact structure of microgel scaffold at the high temperature. The tight aggregate structure of PNTegel would encapsulate the catalytic center, which decreased the exposure of catalytic center to the catalytic substrate and thereby reduced the catalytic rate at the high temperature. Obviously, the catalytic activity of PNTegel changed with the hydrophobicity of the polymer scaffold during the temperature responsive catalytic process. In other words, the structural change of PNTegel played a key role in the regulation of catalytic activity. 


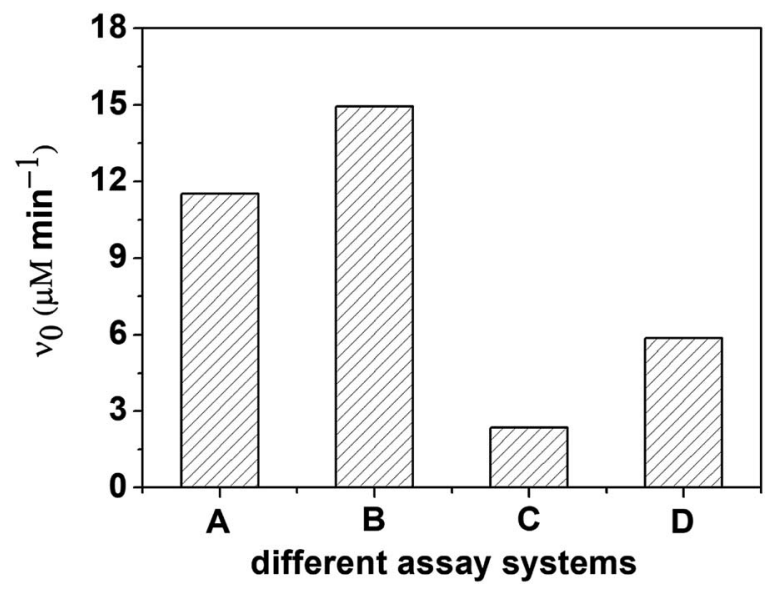

Fig. 10 The catalytic rates $\left(v_{0}\right)$ of the reduction of hydroperoxides (250 $\mu \mathrm{M})$ by TNB and NBT $(150 \mu \mathrm{M})$ in the presence of the PNTegel at $\mathrm{pH} 7.0$ (50 mM PBS) and $37^{\circ} \mathrm{C}$. (A) CUOOH and TNB; (B) CUOOH and NBT; (C) $\mathrm{H}_{2} \mathrm{O}_{2}$ and TNB; (D) $\mathrm{H}_{2} \mathrm{O}_{2}$ and NBT.

In order to further confirm this conclusion, the catalytic rates were measured in systems that contained different catalyzed substrates (Fig. 10). It was found from Fig. 9 that the catalytic activity of PNTegel in the system using NBT as glutathione substrate was higher than that in the system containing TNB when the same peroxide substrate was employed (B > A, D > C). This result indicated that the NBT, with a stronger hydrophobicity, could be more easily reacted as compared with the TNB. Similarly, PNTegel exhibited a higher catalytic activity (A > $\mathrm{C}, \mathrm{B}>\mathrm{D}$ ) when a more hydrophobic $\mathrm{CUOOH}$ was employed as the peroxide substrate. These results suggest that PNTegel exhibits a higher catalytic activity in the reaction system that contains a more hydrophobic substrate. This might be due to the fact that PNIPAM polymer highlighted a hydrophobicity when the temperature was higher than the LCST of PNIAPM, which was likely to gather more hydrophobic substrates into the scaffold of PNTegel to a certain extent. Consequently, the contact of the catalytic center to the catalytic substrates was

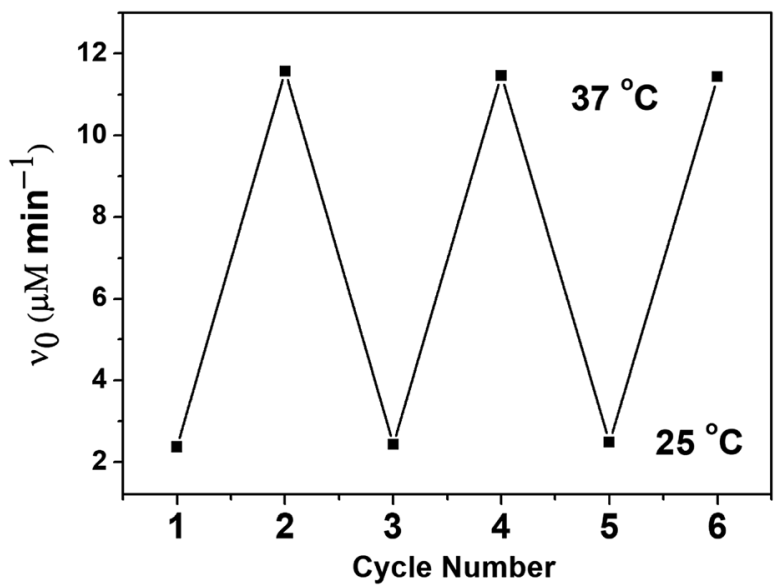

Fig. 11 Changes of the catalytic activity of PNTegel during heating/ cooling cycles between 25 and $37^{\circ} \mathrm{C}$. increased, which promoted the catalytic rate of PNTegel. Therefore, the change trend of catalytic activity measured in different catalytic reaction systems further proved that the hydrophobicity of the polymer scaffold in PNTegel was an important factor for altering the catalytic activity.

For the temperature responsive biomimetic GPx, the reversibility of the catalytic behavior with temperature was also an important property. Therefore, the reversibility of catalytic activity for PNTegel was investigated during heating/cooling processes (see Fig. 11). It was found that the catalytic activity of PNTegel did not change substantially when the temperature was converted repeatedly between 25 and $37{ }^{\circ} \mathrm{C}$.

\section{Conclusions}

In this work, a new strategy for construction of biomimetic GPx using a one-pot synthesis was successfully explored. The prepared biomimetic GPx, PNTegel, exhibited a typical temperature responsive catalytic activity. The highest catalytic activity $\left(11.51 \mu \mathrm{M} \mathrm{min}{ }^{-1}\right)$ in the system containing TNB and $\mathrm{CUOOH}$ was obtained at $37{ }^{\circ} \mathrm{C}$ during the temperature responsive process. The structure change of the polymer scaffold of PNTegel that induced by the temperature is mainly responsible for the change of the catalytic activity. Because of the absence of the hydrophobic microenvironment for gathering the reaction substrates, PNTegel presented a low catalytic activity at low temperature $(<\mathrm{LCST})$. Whereas a high temperature $\left(>37^{\circ} \mathrm{C}\right)$ lead to a compact structure of PNTegel, which obstructs the contact of the catalytic center and substrates and also decreases the catalytic activity. This study may provide important theoretical supports for the preparation of highly effective antioxidant drugs.

\section{Conflicts of interest}

The authors declare no competing financial interest.

\section{Acknowledgements}

This work was supported by the National Natural Science Foundation of China (51663020), Natural Science Fund for Distinguished Young Scholars of Guangxi Province (2017GXNSFFA198007), the project of Guangxi Colleges and Universities for the Promotion of Foundation Ability of Young Teachers (2018KY0599 and 2019KY0469) and the Project of Guangxi Colleges and Universities Key Laboratory of Beibu Gulf Oil and Natural Gas Resource Effective Utilization (2017KLOG12). The authors also acknowledge the Guangxi Colleges and Universities Innovation Research Team.

\section{Notes and references}

1 G. C. Mills, J. Biol. Chem., 1957, 229, 189-197.

2 O. Epp, R. Ladenstein and A. Wendel, Eur. J. Biochem., 1983, 133, 51-69.

3 H. Sies, Angew. Chem., Int. Ed., 1986, 25, 1058-1071. 
4 H. Sies and H. Masumoto, Adv. Pharmacol., 1996, 38, 229246.

5 H. Sies, Exp. Physiol., 1997, 82, 291-295.

6 Z. P. Wu and D. Hilvert, J. Am. Chem. Soc., 1990, 112, 56475648.

7 L. Engman, D. Stern, I. A. Cotgreave and C. M. Andersson, J. Am. Chem. Soc., 1992, 114, 9737-9743.

8 G. Luo, Z. Zhu, L. Ding, G. Gao, Q. Sun, Z. Liu, T. Yang and J. Shen, Biochem. Biophys. Res. Commun., 1994, 198, 12401247.

9 R. Breslow and S. D. Dong, Chem. Rev., 1998, 98, 1997-2012.

10 T. Kanda, L. Engman, I. A. Cotgreave and G. Powis, J. Org. Chem., 1999, 64, 8161-8169.

11 J. Liu, G. Luo, S. Gao, K. Zhang, X. Chen and J. Shen, Chem. Commun., 1999, 199-200.

12 G. Mugesh, W.-W. du Mont and H. Sies, Chem. Rev., 2001, 101, 2125-2180.

13 T. G. Back and Z. Moussa, J. Am. Chem. Soc., 2003, 125, 13455-13460.

14 S. Mao, Z. Dong, J. Liu, X. Li, X. Liu, G. Luo and J. Shen, J. Am. Chem. Soc., 2005, 127, 11588-11589.

15 X. Liu, L. A. Silks, C. Liu, M. Ollivault-Shiflett, X. Huang, J. Li, G. Luo, Y. M. Hou, J. Liu and J. Shen, Angew. Chem., Int. Ed., 2009, 48, 2020-2023.

16 D. Manna and G. Mugesh, J. Am. Chem. Soc., 2011, 133, 99809983.

17 Y. Bai, Q. Luo, W. Zhang, L. Miao, J. Xu, H. Li and J. Liu, J. Am. Chem. Soc., 2013, 135, 10966-10969.

18 T. Wirth, Angew. Chem., Int. Ed., 2015, 54, 10074-10076.

19 T. Pan, Y. Liu, C. Si, Y. Bai, S. Qiao, L. Zhao, J. Xu, Z. Dong, Q. Luo and J. Liu, ACS Catal., 2017, 7, 1875-1879.

20 Z. Dong, J. Liu, S. Mao, X. Huang, B. Yang, X. Ren, G. Luo and J. Shen, J. Am. Chem. Soc., 2004, 126, 16395-16404.

21 X. Zhang, H. Xu, Z. Dong, Y. Wang, J. Liu and J. Shen, J. Am. Chem. Soc., 2004, 126, 10556-10557.

22 G. Mugesh, A. Panda, H. B. Singh, N. S. Punekar and R. J. Butcher, J. Am. Chem. Soc., 2001, 123, 839-850.

23 Z. Jiang, E. S. Arnér, Y. Mu, L. Johansson, J. Shi, S. Zhao, S. Liu, R. Wang, T. Zhang and G. Yan, Biochem. Biophys. Res. Commun., 2004, 321, 94-101.

24 C. Hou, Q. Luo, J. Liu, L. Miao, C. Zhang, Y. Gao, X. Zhang, J. Xu, Z. Dong and J. Liu, ACS Nano, 2012, 6, 8692-8701.

25 H. Sun, L. Miao, J. Li, S. Fu, G. An, C. Si, Z. Dong, Q. Luo, S. Yu and J. Xu, ACS Nano, 2015, 9, 5461-5469.

26 Y. Wang, H. Xu, N. Ma, Z. Wang, X. Zhang, J. Liu and J. Shen, Langmuir, 2006, 22, 5552-5555.

27 Y. Yin, X. Huang, C. Lv, L. Wang, S. Yu, Q. Luo, J. Xu and J. Liu, Macromol. Biosci., 2010, 10, 1505-1516.

28 S. Yu, Y. Yin, J. Zhu, X. Huang, Q. Luo, J. Xu, J. Shen and J. Liu, Soft Matter, 2010, 6, 5342-5350.

29 Y. Yin, S. Jiao, Y. Wang, R. Zhang, Z. Shi and X. Hu, ChemBioChem, 2015, 16, 670-676.
30 X. Huang, Y. Yin, Y. Tang, X. Bai, Z. Zhang, J. Xu, J. Liu and J. Shen, Soft Matter, 2009, 5, 1905-1911.

31 Y. Yin, S. Jiao, C. Lang and J. Liu, Soft Matter, 2014, 10, 33743385.

32 Y. Yin, S. Jiao, R. Zhang, X. Hu, Z. Shi and Z. Huang, Soft Matter, 2015, 11, 5301-5312.

33 T. D. Vernekar, S. Ghosh and G. Mugesh, Chem.-Asian J., 2016, 11, 72-76.

34 N. Singh, M. Geethika, S. M. Eswarappa and G. Mugesh, Chem.-Eur. J., 2018, 24, 8393-8403.

35 W. Zhou, H. Li, B. Xia, W. Ji, S. Ji, W. Zhang, W. Huang, F. Huo and H. Xu, Nano Res., 2018, 11, 5761-5768.

36 Q. Han, X. Wang, X. Liu, Y. Zhang, S. Cai, C. Qi, C. Wang and R. Yang, J. Colloid Interface Sci., 2019, 539, 575-584.

37 H. Sies, Exp. Physiol., 1997, 82, 291-295.

38 Y. Yin, L. Wang, H. Jin, C. Lv, S. Yu, X. Huang, Q. Luo, J. Xu and J. Liu, Soft Matter, 2011, 7, 2521-2529.

39 H. Zou, H. Sun, L. Wang, L. Zhao, J. Li, Z. Dong, Q. Luo, J. Xu and J. Liu, Soft Matter, 2016, 12, 1192-1199.

40 L. Wang, H. Zou, Z. Dong, L. Zhou, J. Li, Q. Luo, J. Zhu, J. Xu and J. Liu, Langmuir, 2014, 30, 4013-4018.

41 J. Li, C. Si, H. Sun, J. Zhu, T. Pan, S. Liu, Z. Dong, J. Xu, Q. Luo and J. Liu, Chem. Commun., 2015, 51, 9987-9990.

42 R. Xiao, L. Zhou, Z. Dong, Y. Gao and J. Liu, Chin. J. Chem., 2014, 32, 37-43.

43 S. Fu, H. Sun, J. Li, Y. Bai, Q. Luo, Z. Dong, J. Xu and J. Liu, RSC Adv., 2015, 5, 101894-101899.

44 H. Zou, H. Sun, L. Wang, L. Zhao, J. Li, Z. Dong, Q. Luo, J. Xu and J. Liu, Soft Matter, 2016, 12, 1192-1199.

45 J. S. Wang and K. Matyjaszewski, J. Am. Chem. Soc., 1995, 117, 5614-5615.

46 K. Matyjaszewski and J. Xia, Chem. Rev., 2001, 101, 29212990.

47 X. Chu, M. Zhang, N. Zhou, F. Wu, B. Sun and J. Shen, RSC Adv., 2018, 8, 33000-33009.

48 A. Anastasaki, B. Oschmann, J. Willenbacher, A. Melker, M. H. Van Son, N. P. Truong, M. W. Schulze, E. H. Discekici, A. J. McGrath and T. P. Davis, Angew. Chem., Int. Ed., 2017, 56, 14483-14487.

49 J. Wang and J. Li, Mater. Lett., 2017, 186, 178-181.

50 A. Amini, M. Rahimi, M. Nazari, C. Cheng and B. Samali, RSC Adv., 2019, 9, 2772-2783.

51 J. Spěváček, D. Geschke and M. Ilavský, Polymer, 2001, 42, 463-468.

52 X. Huang, Z. Dong, J. Liu, S. Mao, G. Luo and J. Shen, Macromol. Rapid Commun., 2006, 27, 2101-2106.

53 X. Huang, Y. Liu, K. Liang, Y. Tang and J. Liu, Biomacromolecules, 2008, 9, 1467-1473.

54 Y. Yin, S. Jiao, C. Lang and J. Liu, RSC Adv., 2014, 4, 2504025050. 